\title{
Revision of Eupempelus Bates and its transference to Heteropsini Lacordaire (Coleoptera, Cerambycidae, Cerambycinae) ${ }^{1}$
}

\author{
José Ricardo M. Mermudes ${ }^{2}$ \\ Dilma Solange Napp ${ }^{2}$
}

\begin{abstract}
The genus Eupempelus Bates, 1870 is revised and its taxonomic position altered in transferring from Cleomenini Lacordaire, 1869 to Heteropsini Lacordaire, 1869. The genus and the type species, Eupempelus olivaceus Bates, 1870, are redescribed and two new species added: Eupempelus illuminus sp. n., from Bolivia and $E$. spinithorax sp. n., from Ecuador. All the species are illustrated and keyed.

KEY WORDS. Heteropsini, Eupempelus, new species, revision
\end{abstract}

The genus Eupempelus was proposed by BATES (1870) based on a single species, E. olivaceus Bates, 1870, from Amazonas, Brazil. The genus was placed in the tribe Cleomenini Lacordaire, 1869, near Listroptera A.-Serville, 1834 and, since then, has been referred only in catalogues (AURIVILLIUS 1912; BLACKWELDER 1946; MonNÉ 1993; MonNÉ \& GIESBERT 1995).

In recent studies on Neotropical Cleomenini (MERMUDES \& NAPP 2000; NAPP \& MERMUDES, in press) together with an examination of several species of Cleomenes Thomson, 1864 and also other not Neotropical genera, such as Dere White, 1855, Procleomenes Gressit \& Rondon, 1970, Artimpaza Thomson, 1864, Kurarua Gressit, 1936 and Apiogaster Perroud, 1855, it was shown that Eupempelus does not belong in this tribe. Otherwise, among the Neotropical Cerambycinae with finely faceted eyes, Eupempelus is structurally similar to the Heteropsini Lacordaire, 1869. For this reason, Eupempelus is here transferred to the tribe Heteropsini.

The genus Eupempelus and its type species, E. olivaceus, are redescribed and two new species are included: E. illuminus sp. n. (Bolivia) and E. spinithorax sp. n. (Ecuador).

The specimens studied belong to Departamento de Zoologia, Universidade Federal do Paraná, Curitiba (DZUP), Muséum National d'Histoire Naturelle, Paris (MNHN) and Museu Nacional, Universidade Federal do Rio de Janeiro, Rio de Janeiro (MNRJ).

1) Contribuição número 1208 do Departamento de Zoologia, Universidade Federal do Paraná.

2) Departamento de Zoologia, Universidade Federal do Paraná. Caixa Postal 19020, 81531-990 Curitiba, Paraná, Brasil. Bolsista do CNPq. 


\section{Heteropsini Lacordaire, 1869}

\section{Eupempelus Bates, 1870}

Eupempelus Bates, 1870: 401. - Aurivillius, 1912: 428. - Blackwelder, 1946: 583. - Monné, 1993: 78. - Monné \& Giesbert, 1995: 126.

Type species. Eupempelus olivaceus Bates, 1870, by monotypy.

Head moderately long. Frons about as long as wide, oblique, swollen medially near clypeus. Clypeus transverse. Genae at least half as long as lower eye lobes. Eyes finely faceted, deeply emarginate; lower lobes moderately large, upper lobes narrow, well-separated. Antennal tubercles rounded, feebly prominent. Mandibles slender, triangular, acute, coarsely punctocorrugate, fringed along inner border. Apical segment of maxilary and labial palps expanded apically, shorter than the preceding two combined.

Antenae slender, filiform, 11-segmented, reaching or exceeding elytral apices by about two segments in both sexes. Scape cylindrical, not grooved. Segments III-XI cylindrical, not carinate, minutely, densely punctocorrugate, brownish pubescent, II-V with numerous, long, brownish hairs beneath; III slightly longer than V; XI shorter than III.

Prothorax as broad or somewhat broader than long; in males moderately rounded at sides, either unarmed or with a small, acute tubercle on each side at middle; in females with a well-developed, acute tubercle at sides. Pronotum raised, with four lateral gibbosities. Prosternum with sexual punctation in males; intercoxal process slightly wider than $1 / 3$ of procoxa, parallel-sided, feebly expanded apically, apical border barely angulate. Anterior coxal cavities somewhat angulate at sides, open behind. Mesosternum with intercoxal process plane, about $2 / 3$ as wide as mesocoxa, somewhat narrowed between mesocoxae, notched medially at apex to fit metasternum.

Elytra about three times as long as the width across humeri, subparallel or somewhat expanded behind middle, dorsally costate, the apices conjointly rounded truncate; somewhat raised at basal $1 / 4$ on each side of the suture and impressed inside humeri. Humeri rounded. Scutellum small, quadrangular, broadly rounded at apex; surface microcorrugate.

Legs slender. Femora linear, neither carinate nor grooved, acutely bidentate at apices. Metafemora reaching or slightly exceeding elytral apices in males; shorter than elytra in females. Tibiae cylindrical, feebly impressed. Tibial spurs short, the inner longer. First segment of metatarsi slightly longer than the following two combined.

Abdomen 5-segmented. Urosternite I as long as II, the intercoxal process narrow, acuminate. Urosternite $\mathrm{V}$ tranverse, rounded at apex in males; elongate, somewhat convergent apicad, rounded truncate at apex in females.

Remarks. The transference of the genus Eupempelus, from Cleomenini to Heteropsini, is based on the following characters which are shared with most of the South American genera of Heteropsini: 1) apical segment of palps short and expanded apically; 2) antennae filiform, with the third segment longer than the following; 3 ) prothorax sexually dimorphic; 4) anterior coxal cavities angulate at sides, open behind; 
5) femora linear, not carinate; 6) elytra not carinate laterally, the epipleura declivous neither carinate nor asperate; 7) mesosternum with the intercoxal process narrowed between mesocoxae and notched medially at apex; 8) urosternites transverse, the first as long as second, with the intercoxal process narrow and acuminate.

In the Neotropical Cleomenini the apical segments of the palps are cylindri$\mathrm{cal}$, attenuate at apex and base; the segments of the antennae are at least expanded apically, the anterior coxal cavities are closed behind and at most barely angulate at sides; the prothorax is similar in both sexes; the femora are pedunculate clavate, with the peduncles carinate and usually grooved; the elytra are flattened and costate at sides with the epipleura conspicuously vertical, costate and asperate; the intercoxal process of the mesosternum is prominent, vertical in front, wider than mesocoxa and truncate apically; the abdomen is oval, with the first urosternite at least as long as the following two combined, and the intercoxal process is broadly rounded. Within the Heteropsini, Eupempelus get close to Allodemus Zajciw, 1962 and Homogenes Thomson, 1862.

\section{Key to the species of Eupempelus}

1. Prothorax uniformly black; pronotum densely clothed with black pubescence, velvet-like. (Integument all-black, the elytra clothed with whitish pubescence. Prothorax rounded at sides in males) (Figs 5-6). PERU, Bolivia, BRAZIL (Pará) .................................... E. illuminus sp. $\mathbf{n}$.

1'. Prothorax immaculate reddish; pronotum reddish pubescent ........... 2

2. Elytra metallic dark green, vaguely costate, inconspicuously brownish pubescent. Prothorax rounded at sides in male, tuberculate in female. Gibbosities of the pronotum weakly prominent. Antennae longer than body in both sexes. Tibiae carinate (Figs 1-2). Brazil (Amazonas, Mato Grosso) .......... E. olivaceus Bates, 1870

2'. Elytra blackish, strongly costate, densely clothed with witish pubescence on distal 2/3. Prothorax tuberculate at sides on both sexes. Gibbosities of the pronotum strongly prominent. Antennae as long as body in male, conspicuously shorter in female (Figs 3-4). ECUADOR ........ E. spinithorax $\mathbf{s p .} \mathbf{n}$.

\section{Eupempelus olivaceus Bates, 1870}

Figs 1-2

Eupempelus olivaceus Bates, 1870: 401. - Aurivillius, 1912: 428. - Blackwelder, 1946: 583. - Monné, 1993: 78. - Monné \& Giesbert, 1995: 126.

Female. Integument opaque. Head, antennae and legs greenish black. Prothorax and back of the head orangish red. Elytra and scutellum metallic dark green. Metasternum and urosternites metallic green. Mesosternum brownish. Head elongate, microcorrugate, sparsely orangish red pubescent. Frons longer than broad. Genae as long as lower eye lobes. Antennae exceeding elytral apices by one segment. Scape half as long as segment III; finely, shallowly punctate, subglabrous. Segments III-IV with a short spine at inner apex. Segment III longer than V; IV 
slightly shorter than V; VI-XI subequal and decreasing in length; XI about $2 / 3$ as long as segment III.

Prothorax as long as broad, with an acute tubercle on each side at middle. Pronotum opaque, impunctate, clothed with very short, recumbent, orangish red pubescence, intermingled with scattered short, erect hairs. Pronotal gibbosities rounded: two antemedian, weakly prominent and separated from each other, and two near base, more prominent and separated as well. Prosternum opaque, microcorrugate, inconspicuously pubescent. Mesosternum, metasternum and urosternites microcorrugate, pubescent, with sparse asperate punctures, each bearing a short semierect hair.

Elytra somewhat convex, subparallel. Each elytron with a straight, weakly prominent costa, beginning at basal third and vanishing toward apex. Surface opaque, with moderately fine, moderately dense, deep punctures, almost corrugate at basal third; pubescence inconspicuous. Epipleuron and apices declivous.

Femora microcorrugate, opaque, clothed with brownish pubescence, intermingled with asperate punctures each bearing a semierect seta. Tibiae carinate, opaque, sparsely pubescent, with asperate punctures and numerous, long setae.

Measurements, in milimeters, female: total length, 12.2; prothorax length, 2.3; prothorax width, 2.5; elytral length, 8.7; humeral width, 2.8 .

Holotype male. The redescription below is based on color photographs and on the original description (BATES 1870: 401). The measurements and some other informations on morphological features were provided by Dr. M.A. Monné who examined the holotype.

Form elongate. Integument olivaceous green, subopaque, prothorax orangish red. Head elongate. Antennae exceeding elytral apices by at least two segments. Scape half as long as segment III. Segment III longer than V; IV slightly shorter than V; segments VI-X subequal and decreasing in length, XI little longer than half of III. Prothorax as long as broad, rounded and unarmed at sides. Pronotum with five weakly prominent gibbosities: four rounded, lateral and one median, elongate. Elytra elongate, subparallel, microcorrugate and finely, moderately densely punctate. Each elytron vaguely bicostate, weakly impressed between costae, the costae straigth. Apices declivous, truncate. Metafemora barely exceeding elytral apices. Tibiae carinate.

Measurements, in milimeters: total length, 11.5; prothorax length, 2.3; prothorax width, 2.3; elytral length, 7.7; humeral width, 2.6.

Types. BATES (1870) based on a single male from "Ega" [now Tefé], Amazonas (MNHN), which is labelled as follows: 1) Ega; 2) Eupempelus olivaceus Bates; 3) Ex. Musaeo H.W. Bates, 1892. According to BATES (1870: 401) the specimen was found "At fragrant flowers in the forest, in company with species of Odontocera and Agaone."

Remarks. Eupempelus olivaceus may be recognized by the combination of the following characters: elytra, metasternum and urosternites metallic green, the former being inconspicuosly pubescent and vaguely costate; prothorax reddish, unarmed at sides in male; tibiae carinate.

Material examined. BraZIL. Mato Grosso: Diamantino (Alto Rio Arinos), 1 female (compared with holotype), X.1983, B. Silva leg. (MNRJ). 


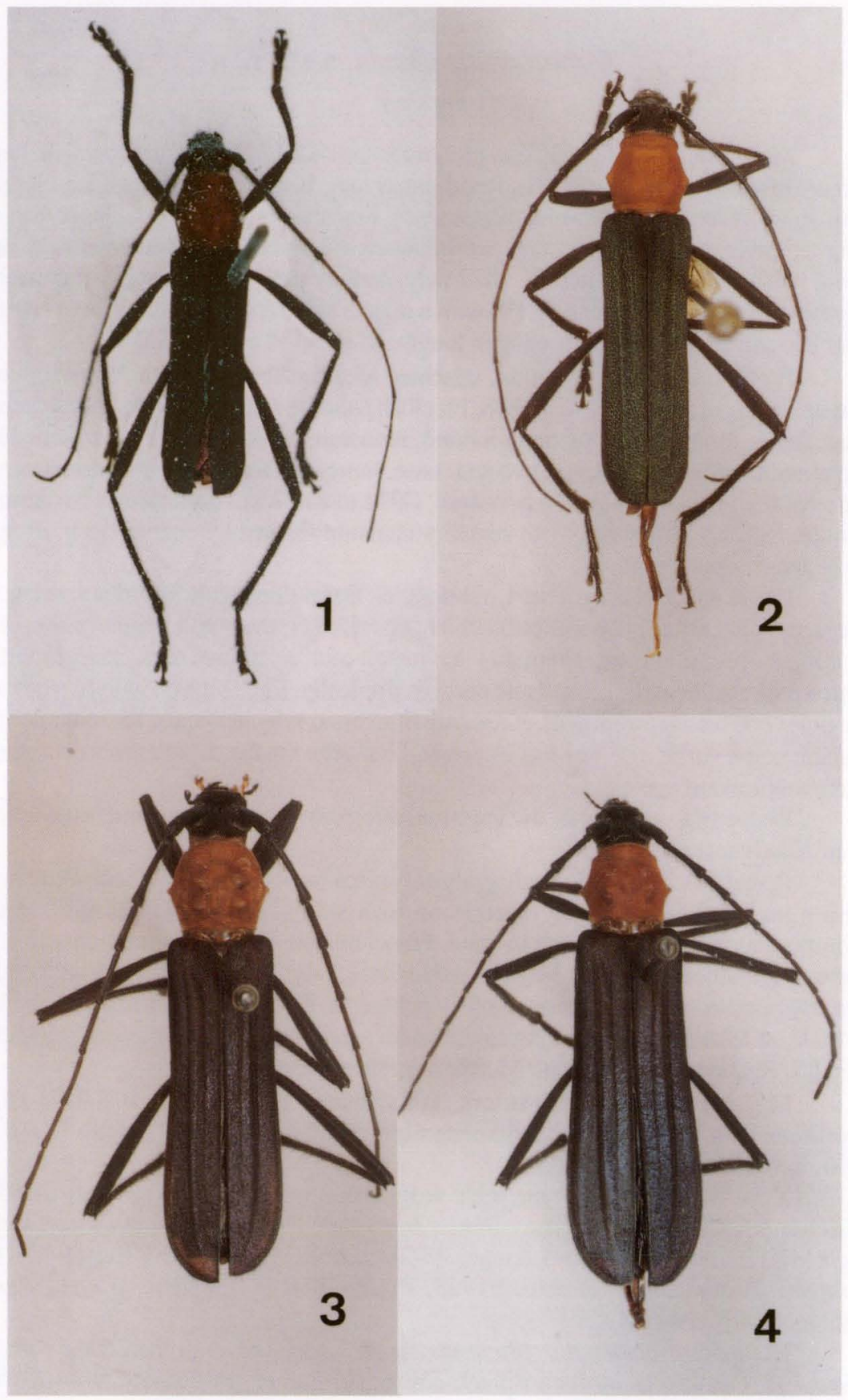

Figs 1-4. (1) Eupempelus olivaceus, male holotype (reproduction of a photograph made at MNHN); (2) E. olivaceus, female; (3-4) E. spinithorax sp. n., male holotype and female paratype. 


\section{Eupempelus illuminus sp. $\mathbf{n}$.}

Figs 5-6

Male. Integument black, opaque. Antennae and elytra black to brownish. Legs and urosternites feebly bluish. Head moderately long, densely microcorrugate, clothed with short, recumbent, brownish pubescence. Frons as long as broad. Genae half as long as lower eye lobes. Antenae exceeding elytral apices by two segments. Scape about half as long as segment III, shallowly, densely punctulate, sparsely pubescent. Segment III about $1 / 4$ longer than IV, with a minute spine at inner apex; V little shorter than III; segments VI-X decreasing in length, XI about $3 / 4$ as long as III.

Prothorax as long as broad, unarmed at sides. Pronotum uniformly microcorrugate, densely clothed with short, blackish pubescence, velvet-like with scatered erect setae. Pronotal gibbosities rounded, moderately prominent: two antemedian separated from each other, and two near base, somewhat transverse and more lateral. Sides of the prothorax with deep, coarse, dense to confluent punctures. Prosternum opaque, whitish pubescent, with sexual punctation formed by coarse, deep, irregularly densely punctures.

Elytra somewhat flattened, subparallel. Basal third with fine, deep, dense to corrugate punctures, pubescence blackish; distal $2 / 3$ clothed with whitish pubescence almost obscuring integument and leaving on each ely tra two dark, straight vittae which are broader at basal third and narrowed apically. Each elytron with two costae, the outer one feebly prominent, extending from basal $1 / 4$ to near apex, the inner poorly conspicuous; surface somewhat impressed between costae. Epipleuron declivous, narrowed toward apex.

Shape and vestiture of the legs, mesosternum, metasternum and urosternites as in E. olivaceus.

Female. Antennae exceeding elytral apices by about one segment. Prothorax with a well-developed, acute tubercle on each side at middle. Gibbosities of the pronotum more prominent than in male. Pronotum and sides of the prothorax microcorrugate, clothed with short, blackish pubescence, velvet-like. Prosternum uniformly, densely microcorrugate, inconspicuously pubescent. Elytra proportionally longer than in male, at least 3.5 times as long as the width across humeri; conspicuously parallel at sides. Epipleuron subvertical. Metafemora shorter than elytra.

Measurements, in milimeters, male/female: total length, 10.8/14.4-16.2; prothorax length, 2.2/2.7-2.8; prothorax width, 2.2/2.8-3.2; elytral length, 7.7/10.812.0; humeral width, 2.5/3.3-3.7.

Type material. Holotype male from BoLIVIA, Yungas: Nigrillani, I.1950, Williner leg. (MNRJ). Paratypes: PERU, Amazonas: Huambo, 1 female, Staudinger leg. (MNHN); Junin: Satipo, 1 female, 1940, ex. coll. A. Maller (MNRJ). BoliviA, Yungas: Chulumani, 1 female, I.1948, Bridarolli leg. (DZUP). BRAZIL, Pará: Santarém, 1 female (MZSP).

Remarks. Eupempelus illuminus sp. n., shares several characters with $E$. olivaceus, but differs by its all-black color, with the elytra densely clothed with whitish pubescence, the velvety pronotum and the not carinate tibiae.

Etymology. The specific name is from Latin, meaning without light, dark, used here in reference to the black color of the integument. 

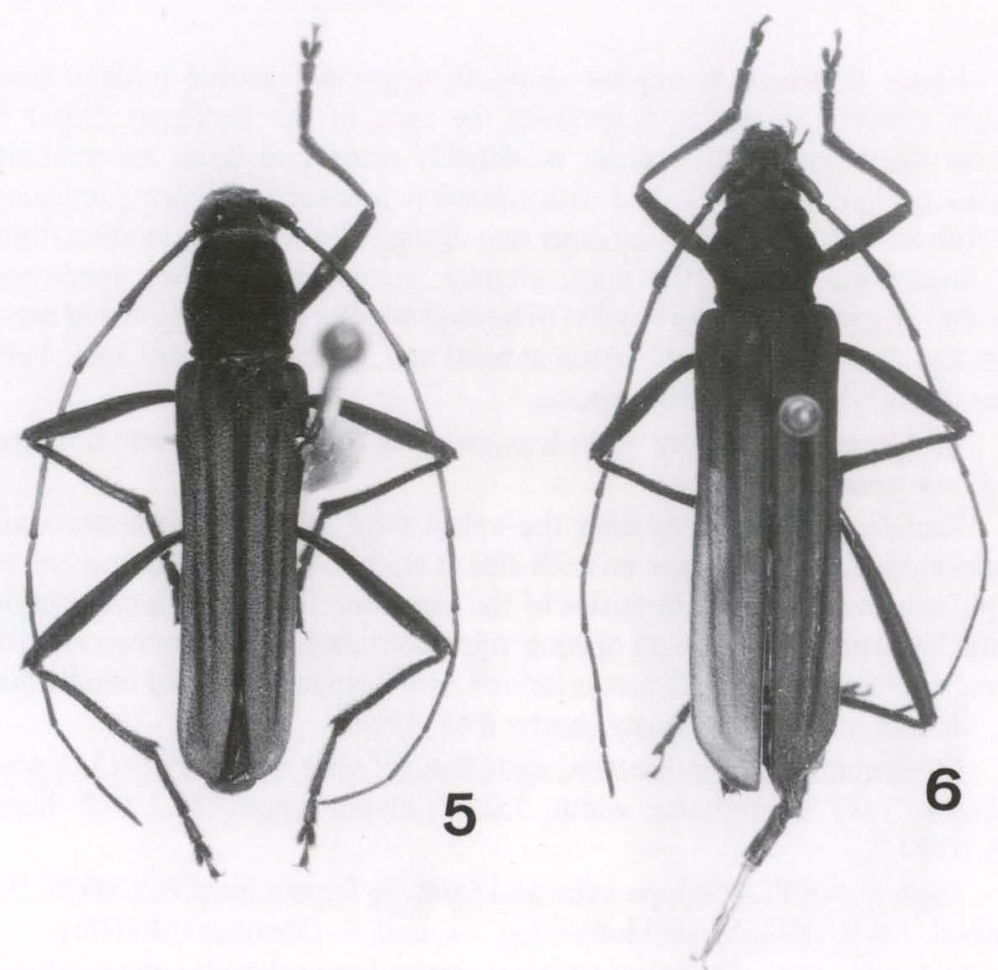

Figs 5-6. Eupempelus illuminus sp. n. (5) male holotype; (6) female paratype.

\section{Eupempelus spinithorax sp. $\mathbf{n}$.}

Figs 3,4

Male. Integument black, opaque. Prothorax and back of the head orangish red. Elytra and femora with very feeble violaceus reflections. Urosternites bluish dark. Head moderately long, densely microcorrugate, clothed with short, blackish pubescence. Frons broader than long. Genae half as long as lower eye lobes. Antennae reaching elytral apices. Scape slightly enlarged from base to apex, as long as $2 / 3$ of segment III; finely, shallowly, densely punctocorrugate, subglabrous. Segments III-IV with a short spine at inner apex. Segment III about 1/3 longer than IV, V-VII subequal and longer than IV, VIII-X decreasing in length, XI short, about half as long as III.

Prothorax broader than long, with a small, acute tubercle on each side at middle. Pronotum uniformly, densely microcorrugate, clothed with short, erect orangish red pubescence. Pronotal gibbosities strongly prominent, subacuminate, the basal pair somewhat smaller and close to the anterior pair. Sides of the prothorax with deep, dense, coarse punctures extending to the pronotum in front of the anterior gibbosities. Prosternum shiny, whitish pubescent, with sexual punctation formed by deep, coarse, dense to confluent punctures. 
Elytra flattened, somewhat sinuously expanded behind middle, broadly rounded truncate at apices, surpassing the apex of the abdomen. Basal third microcorrugate with fine, shallow, moderately dense punctures, the pubescence inconspicuous; distal $2 / 3$ clothed with whitish pubescence, obscuring integument. Each elytron with two costae; the outer one strongly prominent, extending from the basal impression to near the apex, slightly sinuous at base; the inner poorly conspicuous, extending from basal $1 / 4$ to beyond middle; surface impressed between costae. Epipleuron somewhat vertical at basal half, narrowed toward apex. Femora shorter than elytra. Tibiae not carinate.

Sculpture and vestiture of the legs, meso- and metasternum and urosternites as in E. olivaceus.

Female. Antennae reaching the apical third of elytra. Prothorax with a well-developed, acute tubercle on each side at middle; sides microcorrugate, orangish pubescent. Anterior gibbosities of the pronotum larger and more prominent than the basal ones. Prosternum opaque, microcorrugate, whitish pubescent. Elytra 3.5 times as long as the width across humeri, more expanded behind middle than in male. Metafemora conspicuously shorter than elytra.

Measurements, in milimeters, male/female: total length, 17.0/17.2; prothorax length, 3.0/3.2; prothorax width, 3.6/3.8; elytral length, 12.2/14.0; humeral width, 3.8/4.2.

Type material. Holotype male and paratype female from ECUADOR, Baños à Canelos, IX-X/1894, M. de Mathan leg., ex. coll. R. Oberthür (MNHN).

Remarks. Eupempelus spinithorax is easily distinguished by the combination of: 1) reddish prothorax, tuberculate at sides in both sexes, with the gibbosities of the pronotum strongly prominent and subacuminate; 2) blackish elytra, densely clothed with whitish pubescence and strongly costate; 3 ) metafemora shorter than elytra in both sexes, and 4) antennae as long as body in male and conspicuously shorter in female. Besides, E. spinithorax is the only species knowing to occur in Ecuador, for a while.

Etimology. The specific name refers to the presence of a spine-like tubercle on each side of the male prothorax.

ACKNOWLEDGMENTS. We deeply thank to Dr. M.A. Monné (MNRJ) for the informations about the holotype of Eupempelus olivaceus and also for providing most of the specimens studied here. Thanks are extended to Dr. J.M. Menier (MNHN) for the loan of material, and to Dr. A.M. Sakakibara (DZUP) who kindly revised the English manuscript and took the photos.

\section{REFERENCES}

Aurivillius, C. 1912. Coleopterorum Catalogus. 39. Cerambycinae. Berlin, W. Junk, 574p.

BLACKWELDER, R.E. 1946. Checklist of the coleopterous insects of Mexico, Central America, the West Indies and South America. Part 4. Bull. U.S. Nat. Mus. 185: 551-763.

BATES, H.W. 1870. Contributions to an insect fauna of the Amazon Valley (Coleoptera, Cerambycidae).

Trans ent. Soc. London 1870: 391-444.

MERmudES, J.R.M. \& D.S. NAPP. 2000. Review of the genus Haenkea Tippmann (Coleoptera, 
Cerambycidae, Cerambycinae, Cleomenini). Coleopts Bull. 54 (4): 511-519.

MonnÉ, M.A. 1993. Catalogue of the Cerambycidae (Coleoptera) of the Western Hemisphere. Part IX. São Paulo, Sociedade Brasileira de Entomologia, 131p.

Monné, M.A. \& E. GiSBERT. 1995. Checklist of the Cerambycidae and Disteniidae (Coleoptera) of the Western Hemisphere. Burbank, Wolfsgarden Books, XIV+419p.

NAPP, D.S. \& J.R.M. MERMUDES. (in press). Revision of the genus Listroptera Audinet-Serville and description of Aguassay, new genus (Coleoptera, Cerambycidae, Cleomenini). Coleopts. Bull.

Recebido em 27.IV.2000; aceito em 06.IV.2001. 